\title{
Ventriküloperitoneal Şant ve Gebelik: Olgu Sunumu
}

\author{
Ventriculoperitoneal Shunt and Pregnancy: a Case Report
}

\section{Hicran Acar ŞİRİNOGLU ${ }^{1}$, Oya PEKİN ${ }^{1}$, Deniz ŞİRİNOGLU ${ }^{2}$ Sevcan Arzu ARINKAN ${ }^{1}$, Gökhan ÜNVER ${ }^{1}$}

1. Zeynep Kamil Kadın ve Çocuk Hastalıkları Eğitim ve Araştırma Hastanesi, Perinatoloji Kliniği, İstanbul, Turkiye

2. Okmeydanı Eğitim ve Araştırma Hastanesi, Beyin Cerrahisi Kliniği, İstanbul, Turkiye

\section{$\ddot{O Z E T}$}

Hidrosefali sebebiyle serebrospinal şantı olan kadinların gebelik oranlarl giderek artmaktadır. Temel olarak maternal intraabdominal basınç artışı ve intrakraniyal serebrospinal sivı artışı, gebelik ve doğum süresince serebrospinal şantı olan kadinlarda maternal ve fetal komplikasyonlara yolaçabilmektedir. Bu nedenle gebelik öncesi ve gebelik süreci ile doğum dikkatli bir şekilde beyin cerrahisi ile birlikte takip edilmelidir. Olası bir șant fonksiyon bozukluğu tanısı gecikmeden konulmalı ve zamanında çözülmelidir. Bu hastaların gebelik süreçleri ve sonuçları hakkında literatürde yeterli çalışma bulunmamaktadır. Bu sebeple serebrospinal şantı olan gebelerin doğum şekli ve uygulanacak anestezi şekli ile ilgili yeterli deneyim yoktur. Bu olgu sunumu ile 21 yaşında hidrosefalisi ve ventrikuloperitoneal şantı olan gebenin yönetimi tartışılmıştır. Ventriküloperitoneal şantı olan ve nörolojik bir problemi olmayan gebelerde normal doğum tercih edilmesi ve obstetrik nedenler dışında doğuma müdahele edilmemesi önerilmektedir.

Anahtar Kelimeler: ventrikuloperitoneal sant, gebelik, normal vaginal doğum

\section{ABSTRACT}

Hydrocephalic woman with cerebrospinal fluid shunts are now surviving to reproductive age. Both maternal intra-abdominal pressure and intracranial cerebrospinal fluid increase cause maternal and fetal complications due to cerebrospinal shunt. Therefore gestation period must be followed carefully with brain surgery department. Any shunt unfunction must be diagnosed promptly and solved at on time. There is no enough literature about pregnancies in women with previously placed ventricular shunts for obstructive hydrocephalus. Since there are doubts regarding the mode of delivery, analgesia and anesthesia. We present a case of labor in the 21 year-old woman with hydrocephalus and a ventriculoperitoneal shunt. It is considered that delivery mode of pregnant women with ventriculoperitoneal shunt without any neurological problems is to allow progress naturally and interventions limited to obstetrical reasons alone.

Keywords: ventriculoperitoneal shunt, pregnancy, vaginal delivery

\section{İletişim Bilgileri:}

Sorumlu Yazar: Hicran Acar ŞiRINOĞLU

Yazışma Adresi: Zeynep Kamil Kadın ve Çocuk Hast. Eğt. ve Araştırma Hastanesi, Perinatoloji Kliniği, İstanbul

E-mail: hicranacarus@yahoo.com

Makalenin Geliş Tarihi: 28.12.2014

Makalenin Kabul Tarihi: 29.04.2015

DOI: http://dx.doi.org/10.16948/zktb.42358

\section{GíRIŞ}

Hidrosefali nedeniyle serebrospinal şantı olan gebelerin sayısı giderek artmaktadır. Günümüzde obstruktif hidrosefali nedeniyle serebrospinal şantı olan gebelerin doğum şekli ve uygulanacak anestezi ile ilgili literatürde yeterli çalışma bulunmamaktadır. Ventriküloperitoneal şantlar en çok tercih edilen şantlardır. Gebelik süresince maternal fizyolojide bir çok değişiklik gözlenir. Temel olarak maternal intraabdominal basınç artışı ve intrakraniyal serebrospinal sıvı artışı, gebelik ve doğum süresince serebrospinal şantı olan kadinlarda maternal ve fetal komplikasyonlara yolacabilmektedir. $\mathrm{Bu}$ nedenle gebelik öncesi ve gebelik süreci ile doğum dikkatli bir șekilde beyin cerrahisi ile birlikte takip edilmelidir. Olası bir şant fonksiyon bozukluğu tanısı gecikmeden konulmalı ve zamanında çözülmelidir. Gebelik süresince şantlarda özellikle son trimesterde parsiyel obsturuksiyon gözlenebilir (1). Bu olgu sunumu ile serebrospinal şantı olan bir gebenin takip ve yönetiminin tartışılması amaçlanmıştır.

\section{OLGU}

21 yaşında Gravida 1 olan ve son âdet tarihini bilmeyen, ilk trimester ultrason hesaplamasına göre 37 hafta 6 günlük olan gebe, berrak su gelişi sebebiyle hastanemiz doğum acil polikliniğine başvurmuştur. Hastanın yapılan fizik muayenesinde serviksin yumuşaya başlamış olduğu ve aktif berrak su gelişi gözlendi. Vital bulguları stabil olan hastanın nörolojik muayenesi normal olup ek sistemik bulgu izlenmedi. Yapilan ultrasonografide 36 hafta ile uyumlu, azalmış amnion maii ve bas geliş intrauterin tekil gebelik tespit edildi. Hastanın alınan anamnezinde gebelik süresince dış merkezde beyin cerrahisi polikliniğinde düzenli takiplerini yaptırdığ 1 , birinci ve ikinci trimester tarama testlerinin düşük riskli olduğu ve ikinci trimester ayrintıl1 ultrason incelemesini yaptırmadığ1 öğrenildi. 2004-2006 yılları arasında Non-Hodking Lenfoma sebebiyle kemoterapi alan hastaya hidrosefali gelişmesi sebebiyle ventriküloperitoneal şant takıldığı öğrenildi. Gebeliğin 30. haftasında baş ağrısı, bulantı ve kusma şikâyetiyle diş merkezde beyin cerrahisi polikliniğine başvuran hastaya, şant pompasından ponksiyon yapılarak yaklaşık 
20 cc beyin omurilik sıvısı (BOS) direne edilmiştir. Takiplerinde gebenin şikayeti gerilemiştir. Doğumhanede takip edilen hastaya aktif travaya girdikten sonra düşük doz oksitosin ile indüksiyon uygulandı. Hastanın doğum eylemi süresince şanta bağlı herhangi bir klinik semptomu olmadi. Normal spontan doğum ve epizyotomi ile 2820 gram 8/9 Apgarli tek canlı erkek bebek doğurtuldu. Doğum eylemi ikinci evresinde olası bir doğum süreci uzama riskine karşı vakum hazır bekletildi ve abdominal basınç artışı riski sebebiyle kristaller manevrasından kaçınıldi. Plasenta ve ekleri tam olarak ayrıld1. Lohusa takiplerinde bir özellik olmayan hasta postpartum ikinci gününde taburcu edildi.

\section{TARTISMA}

Hidrosefali nedeniyle serebrospinal şantı olan gebelerin sayıs1 giderek artmakta ve bu hastalarin gebelik takipleri ve doğum şekilleri günümüzde her kadın doğum uzmanının karş1laşabileceği bir durum haline gelmektedir. Landwher ve ark. yaptıkları çalışmalarında serebrospinal şantın gebelik süreci ve doğum şeklini etkilemediğini göstermiştir (2). Wisoff ve ark. 17 gebeyi içeren vaka sunumunda 13 hastada nörolojik komplikasyonlar bildirmiştir. Vakaların, \%60 inda baş ağrısı, \%35 inde mide bulantıs1 ve kusma, $\% 30$ unda letharji ve $\% 20$ sinde ise ataksi rapor edilmiştir. Bu semptomların çoğu konservativ olarak tedavi edilmiștir. Ancak bazı gebelerde akut hidrosefali gelişmiş ve şant günde birkaç defa pompalanmıştır (3). Murakami 2010 yılında yapilan bir vaka sunumunda ventriküloperitoneal şant malfonksiyonu nedeni ile akut hidrosefali gelişen bir gebede konservatif tedavi ile cevap alınamadığ 1 için vetriküloatrial şant operasyonu ile hidrosefalinin düzeldiğini bildirmiştir (4).

Bizim olgumuzda ise 30 . gebelik haftasında baş ağrısı, bulantı ve kusma şikayetleri olan hastada, șanta bağlı hidrosefali düșünülerek 24 saat arayla iki defa şant ponksiyonu yapılmış ve şikayetleri gerileyen hastaya beyin cerrahisi poliklinik kontrolü önerilmiştir. Gebeliğin devamında bir komplikasyon yaşanmamıştır. Hidrosefali sebebiyle şantı bulunan gebeler anne karnındaki basınc artıșı ve gebeliğe bağlı olası serebrospinal sıvı artışı nedeniyle şant disfonksiyonu riskini taşırlar. Bunun sonucu oluşabilecek akut bir hidrosefali riski hayatı tehdit eden ciddi bir klinik acildir. Bu sebeple şantı olan gebeler beyin cerrahisi kliniğiyle ortak olarak takip edilmelidir. Diğer bir tartışma noktası da serebrospinal şantı olan gebelerin doğum şeklidir. 2013 y1lında yayınlanan bir vaka sunumunda Busac ve arkadaşları 32 yaşında serebrospinal şantı olan bir gebenin doğum şeklini tartışmışlar ve herhangi bir semptom gelişmediği sürece en iyi ve doğru doğum şeklini epidural analjezi ile mediolateral epizyotomi ile vakumla gerçekleșen normal spontan doğum olarak rapor etmişlerdir (5). 2014 yılında Vybihal ve arkadaşları şantı bulunan gebelerin doğum şeklini obstruktif bir hidrosefali gelişmediği ve hastanın kliniğinde bir kötüleşme olmadığı sürece ilk tercih olarak normal doğum tercih edilmesi gerektiğini rapor etmişlerdir (6). 2008 yılında Nikalov ve arkadaşları 12 gebeyi içeren vaka serisi sunumunda hidrosefali nedeniyle şant1 bulunan gebelerde ilk tercih olarak doğum şeklini normal spontan vajinal doğum olarak rapor etmişlerdir. Obstetrik nedenler ya da gebenin kliniğinde bir kötüleşme olmadığı sürece sezaryen doğumun gerekli olmadığını tartışmışlardır (7). Bizim olgumuz da benzer şekilde normal spontan vajinal olarak doğurtulmuştur. Doğum sonrası takiplerinde de herhangi bir komplikasyon gelişmeyen hasta bebeğiyle birlikte sağlıklı bir şekilde taburcu edilmiştir.

Sonuç olarak hidrosefali nedeniyle şant1 bulunan gebelerin gebelik takiplerinde şant disfonksiyonuna bağlı akut gelișebilecek bir hidrosefali riski nedeniyle beyin cerrahisi kliniğiyle ortak bir takip hayati önem taşır. Doğum şekli olarak şanta bağlı herhangi komplikasyon gelişmediği sürece ilk tercih epizyotomi ile normal spontan vajinal doğum önerilir. Doğumun 2. evresinin kisaltılması amaciyla vakum kullanilabilir.

\section{KAYNAKLAR}

1- Schiza S, Stamatakis E, Panagopoulou A, Valsamidis D. Management of pregnancy and delivery of a patient with malfunctioning ventriculoperitoneal shunt. J Obstet Gynaecol. 2012;32(1):6-9.

2. Landwehr, Joseph B, Nelson B., Pryde, Peter G., at..Maternal Neurosurgical shunts and pregnancy outcome Obsteric-gynocology 1994.

3. Wisoff JH1, Kratzert KJ, Handwerker SM, Young BK, Epstein F. Pregnancy in patients with cerebrospinal fluid shunts: report of a series and review of the literatüre. Neurosurgery. 1991;29(6):827-31.

4. Murakami M, Morine M, Iwasa T, Takahashi Y, Miyamoto T, Hon PK, Nakagawa Y. Management of maternal hydrocephalus requires replacement of ventriculoperitoneal shunt with ventriculoatrialshunt: a case report Arch Gynecol Obstet. 2010;282(3):339-42.

5. Bursac D, Kulas T, Persec J, Persec Z, Duić Z, Partl JZ, Glavić Z, Hrgović Z, Bojanić K. Pregnancy and vaginal delivery in epidural analgesia in womanwith cerebrospinal fluid shunt. Coll Antropol. 2013;37(4):1343 -5.

6. Vybihal V, Gerychová R, Janků P, Hanoun G, Sova M, Fadrus P, Smrčka M, Keřkovský M. Ceska Gynekol. Pregnancy and delivery in patients with an implanted shunt for hydrocephalus.2014;79(4):309-13.

7. Nikolov A, Surchev Zh, Nalbanski B, Diavolov V, Dimitrov A. Pregnancy and delivery in women with cerebrospinal fluid shunt due to hydrocephalus. Akush Ginekol . 2008;47(2):3-10 